\title{
Assessing the environmental status of Mediterranean temporary ponds in Greece
}

\author{
E. Dimitriou ${ }^{1 *}$, I. Karaouzas ${ }^{1}$, N. Skoulikidis ${ }^{1}$, I. Zacharias $^{2}$ \\ ${ }^{1}$ Hellenic Centre for Marine Research, Institute of Inland Waters, 46.7 km of Athens - Sounio Av., P.O Box 712, 19013, Anavissos, Attika, \\ Greece \\ ${ }^{2}$ University of Ioannina, Department of Environmental and Natural Resources Management, 2 Seferi Str., 30100 Agrinio, Greece
}

\begin{abstract}
Mediterranean temporary ponds (MTPs) are highly distinctive habitats with intermittent and unstable environmental conditions, inhabited by several rare and endemic plant and animal species. Temporary pond ecosystems have been classified as endangered all over the world; nevertheless, they are disappearing at a high rate, especially in the Mediterranean region. MTPs are a priority habitat under the European Union Habitats Directive and thus appropriate management and conservation efforts should be applied. Further research is needed in order to better understand the environmental characteristics and ecology of this habitat which is not always the case in many countries. In this study a range of environmental data were collected from the Greek MTP habitat sites including the altitude, the geology, the representativity, the ecological status and other biological data aiming to assess the environmental status of all known Greek MTPs. Statistical analysis were performed and thematic maps were created using a Geographical Information System (GIS). Greek MTP's were classified according to their characteristics and habitat pressures were identified and further analysed. A comparison between the present environmental status of the MTPs in Greece with the MTPs in other Mediterranean countries was undertaken and relevant conservation and management measures were proposed. The outcome of this study was that a significant percentage of the MTP habitat sites in Greece are at risk mainly due to human activities, such as agricultural pollution, expansion of cropland and water resources over-exploitation. It was concluded that immediate restoration and conservation actions should be taken so as to prevent further ecological degradation.
\end{abstract}

Keywords : Mediterranean Temporary Ponds, ecology, freshwater habitats, phytocommunities, conservation.

\section{Introduction}

Temporary ponds are important habitats that usually occupy depressions, often endorheic, and are particularly well represented in arid, semi-arid and Mediterranean-type regions. These habitats are defined and characterized by their variability in size, hydrological functioning, ephemeral nature of their wet phase (hydroperiod), total dependence on local hydrology and, at the same time, by the absence of any link with permanent aquatic habitats, uniqueness of their vegetation and invertebrate communities (Grillas et al. 2004a, Jakob et al. 2003, Rhazi et al. 2004). Temporary ponds

\footnotetext{
* Corresponding author :

E-mail: elias@ath.hcmr.gr.
}

are isolated habitats, which are also important environments for many migratory birds (Madhyastha et al. 2000, Grillas et al. 2004). On a global scale, temporary ponds are common in northern Europe (Angélibert et al. 2004, Nicolet et al. 2004, Williams 1997), North America (Belk 1998, Graham 2002, Leidy and White 1996, Roshier et al. 2001), Australia (Warwick \& Brock 2003) and South Africa (Lahr et al. 2000a, Lahr et al. 2000b, Rhazi et al. 2001b).

The Mediterranean Temporary Pond (MTP) is a priority freshwater habitat type (3170*, NATURA 2000), that has the aforementioned characteristics and is mainly encountered in Mediterranean countries. MTPs occupy very shallow depressions, which exist only during winter and sometimes spring, while their vegetation mainly comprises Mediterranean therophytic and geophytic species (EC, 2003). Apart from natu-

Article available at http://www.limnology-journal.org or http://dx.doi.org/10.1051/limn/2006004 
ral hydrologic and climatic events, which are the major biological regulatory factors, anthropogenic activities pose serious threats to these habitats. On a global scale, temporary ponds are often neglected due to their ephemeral character. Abandonment of traditional land and water uses, unsustainable management practices, hydrologic alterations (i.e. water abstraction), among others, may lead to the degradation and elimination of these valuable ecosystems (King 1996, Brendonck \& Williams 2000, Blaustein \& Schwartz 2001, Beja \& Alcazar 2003).

In Greece, agricultural intensification during the last 3 decades in combination with public ignorance and lack of environmental education regarding the value of the MTPs, have led to a continuous increase of habitat pressures and to their consequent deterioration. The aim of this study was to assess the current status of MTP habitats in Greece, to examine their dominant characteristics and similarities and to identify potential threats through the use of the Geographical Information System (GIS) and the application of statistical methods. A qualitative comparison of these characteristics and threats with those of the equivalent habitat type in other Mediterranean countries was conducted. Potential management and conservation measures were discussed based on relevant international experience.

\section{Methods}

\section{Description of the Study Area}

The MTP sites are concentrated in the southeastern part of Greece (fig. 1, table 1) due to the dominant climatic conditions of the area (semi-dry) favoring the habitats' typical hydrologic characteristics (alterations between wet and dry periods). In this study MTP sites coincide with the relevant Natura 2000 sites where the priority habitat of Mediterranean Temporary Ponds (Natura code: 3170 ) has been found. Thus, 'site' is defined as an area comprising either a cluster of ponds or an individual pond as mapped by the Natura 2000 project teams. As illustrated in Figure 1, only 1 out of 18 sites is located in the mainland, whereas the island of Crete has the highest presence of MTP's from any other region of the country $(17 \%)$. The amount of rainfall in these islands rarely exceeds $600 \mathrm{~mm}$ a year and the prolonged dry period prevents permanent dominance of aquatic vegetation. The complex of the Cyclades islands, located in the centre of the Aegean sea, hosts five MTP sites (28\% of the total number of sites) while another $28 \%$ of the MTPs is found in the northern Aegean (fig. 1). Gavdos Island, which is the southern edge of Greece presents several MTPs in the form of rock pools that develop in small scale calcareous depressions and have mostly species from the Zannichellion class.

\section{Data analysis}

The Natura 2000 database of Greece, as well as data from LIFE-Nature projects (LIFE04NAT/GR/000105 and LIFE99NAT/FR/72049) were used as a basis for this study. Particularly, information regarding the exact location of the MTP sites, their vegetation composition, representativity of typical phytocommunities, eco-status, threats, geological substrate and altitude have been acquired. Ecological status represents the pressures imposed on the habitat by assessing the existing anthropogenic activities and land uses as well as the flora composition at each site. According to the intensity of pressures and threats observed by the Natura 2000 project teams, through field surveys, bibliographic research and existing cartographic data, the MTP sites were classified into 4 quality categories (excellent, good, medium and at risk). Representativity is a dimensionless index that has been used during the development of NATURA 2000 database (EC/266/97) in order to assess the presence of the habitat's typical phytocommunities in the study areas.

All the above data has been initially elaborated in a statistical package (Biodiversity Professional software; McAleece 1997) by applying descriptive statistics, frequency and cluster analysis to derive information about common characteristics at the various sites and potential trends amongst the examined parameters.

The aforementioned data was also imported in ArcView software (GIS) in a tabular form to analyse the spatial component and distribution of the MTP's characteristics. Thematic maps have been produced, presenting the distribution of phytocommunities in the Greek MTP sites, the geological substrate and their eco-status. An analysis of the resulted maps followed to indicate the spatial aspect of the observed trends so as to identify potential relationships between the latitudinal gradient and specific phytocommunities occurrence as well as between island/continental sites and habitats' eco-status and pressures. The latter effort incorporated the socioeconomic component in the assessment since pressures such as tourism is mostly encountered in small and medium sized islands while agriculture can be a significant threat factor in continental areas and in large islands.

All the available information was combined to assess the current status of MTP sites in Greece, with an emphasis on their vegetation and observed pressures. A qualitative comparison was conducted between Greek MTPs and MTPs of other Mediterranean coun- 


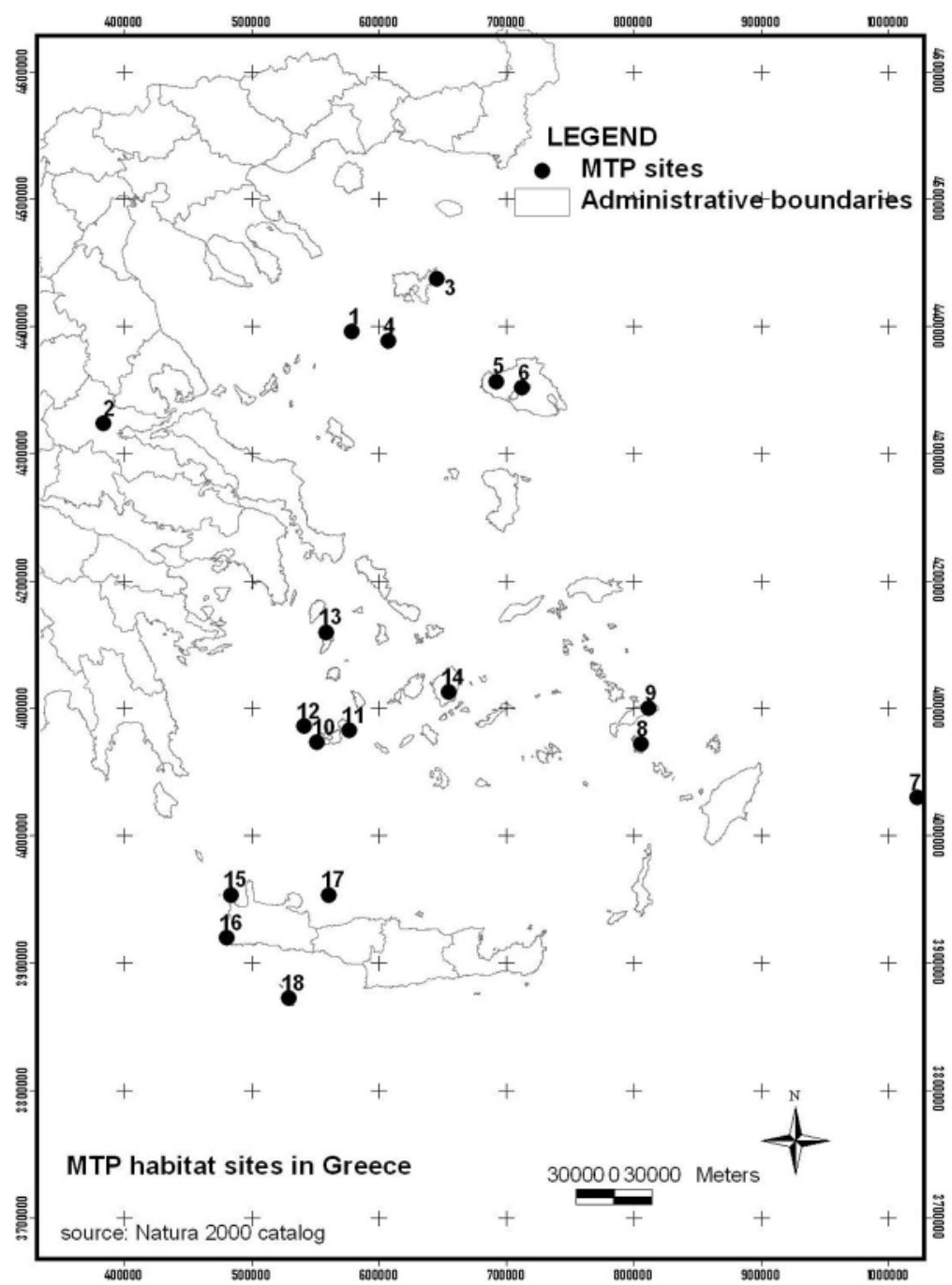

Fig. 1. Location of Greek Mediterranean Temporary Ponds.

tries by the outcomes of the aforementioned analysis (for the Greek sites) and bibliographic data and relevant studies (for the non-Greek sites). Management and conservation issues were also investigated in order to tackle the identified problems and contribute to the restoration of the priority habitat.

\section{Results}

\section{Phytocommunities of Greek MTPs}

A total of 95 plant species were identified in all the Greek MTP sites. Species belonging to the Isoetion phytocommunity (Callitriche brutia Petagna, Tillaea vaillantii Willd., Elatine macropoda Guss, Pilularia minuta Durieu, Isoetes hystrix Bory, etc.), were the most common and dominant phytocommunity of Greek MTPs (fig. 2), followed by species of the Nanocyperion phytocommunity (Juncus bufonius L., Trifolium nigrescens Viv., Cyperus fuscus L., Juncus hybri$d u s$ Brot., etc.). Species of the Isoeto-Nanojuncetea and Zannichellion phytocommunities accounted for $7 \%$ individually. Carex divisa Huds., Bellium minutum L. , Lotus conimbricensis Brot., and Spergularia bocconei Scheele, were the representative species for the former, whereas the latter included Zannichellia palustris L., Ranunculus rionii L. and Zannichellia pedunculata Rchb. Finally, the Thero-Brachypodietalia 
Table 1. MTP site codes, names and size (source : Natura 2000 database).

\begin{tabular}{|c|c|c|c|}
\hline $\begin{array}{l}\text { SITE } \\
\text { CODE }\end{array}$ & $\begin{array}{l}\text { NATURA } \\
\text { CODE }\end{array}$ & SITE NAME & AREA (ha) \\
\hline Site 1 & GR1430004 & $\begin{array}{l}\text { ETHNIKO THALASSIO PARKO ALONNISOU - } \\
\text { VOREION SPORADON, ANATOLIKI SKOPELOS }\end{array}$ & 249145.62 \\
\hline Site 2 & GR2440002 & $\begin{array}{l}\text { KOILADA KAI EKVOLES SPERCHEIOU - } \\
\text { MALIAKOS KOLPOS }\end{array}$ & 47547.07 \\
\hline Site 3 & GR4110001 & $\begin{array}{l}\text { LIMNOS: CHORTAROLIMNI - LIMNI ALYKI KAI } \\
\text { THALASSIA PERIOCHI }\end{array}$ & 18231.66 \\
\hline Site 4 & GR4110002 & $\begin{array}{c}\text { AGIOS EFSTRATIOS KAI PARAKTIA THALASSIA } \\
\text { ZONI }\end{array}$ & 6283.75 \\
\hline Site 5 & GR4110003 & $\begin{array}{l}\text { LESVOS: DYTIKI CHERSONISOS - } \\
\text { APOLITHOMENO DASOS }\end{array}$ & 20974.07 \\
\hline Site 6 & GR4110004 & $\begin{array}{l}\text { LESVOS: KOLPOS KALLONIS KAI CHERSAIA } \\
\text { PARAKTIA ZONI }\end{array}$ & 18297.82 \\
\hline Site 7 & GR4210004 & $\begin{array}{l}\text { KASTELLORIZO KAI NISIDES RO KAI STRONGYLI } \\
\text { KAI PARAKTIA THALASSIA ZONI }\end{array}$ & 1769.68 \\
\hline Site 8 & GR4210007 & $\begin{array}{l}\text { NOTIA NISYROS KAI STRONGYLI KAI PARAKTIA } \\
\text { THALASSIA ZONI }\end{array}$ & 4055.74 \\
\hline Site 9 & GR4210008 & $\begin{array}{l}\text { KOS: AKROTIRIO LOUROS - LIMNI PSALIDI - } \\
\text { OROS DIKAIOS - ALYKIIPARAKTIA THALASSIA } \\
\text { ZONI }\end{array}$ & 10138.24 \\
\hline Site 10 & GR4220005 & PARAKTIA ZONI DYTIKIS MILOY & 5328.25 \\
\hline Site 11 & GR4220006 & NISOS POLYAIGOS-KIMOLOS & 13855.78 \\
\hline Site 12 & GR4220007 & NISOS ANTIMILOS-THALASSIA PARAKTIA ZONI & 1260.76 \\
\hline Site 13 & GR4220010 & $\begin{array}{l}\text { VOREIODYTIKI KYTHNOS: OROS ATHERAS- } \\
\text { AKROTIRIO KEFALOS KAI PARAKTIA ZONI }\end{array}$ & 2855.19 \\
\hline Site 14 & GR4220014 & $\begin{array}{l}\text { KENTRIKI KAI NOTIA NAXOS: ZEFS KAI VIGLA } \\
\text { EOS MAVROVOUNI KAI THALASSIA ZONI (ORMOS } \\
\text { KARADES-ORMOS MOUTSOUNAS) }\end{array}$ & 8668.41 \\
\hline Site 15 & GR4340001 & $\begin{array}{l}\text { IMERI KAI AGRIA GRAMVOUSA - TIGANI KAI } \\
\text { FALASARNA - PONTIKONISI, ORMOS LIVADIA- } \\
\text { VIGLIA }\end{array}$ & 5781.30 \\
\hline Site 16 & GR4340002 & $\begin{array}{c}\text { NISOS ELAFONISOS KAI PARAKTIA THALASSIA } \\
\text { ZONI }\end{array}$ & 271.79 \\
\hline Site 17 & GR4340010 & $\begin{array}{l}\text { DRAPANO (VOREIOANATOLIKES AKTES) - } \\
\text { PARALIA GEORGIOUPOLIS - LIMNI KOURNA }\end{array}$ & 4430.51 \\
\hline Site 18 & GR4340013 & NISOI GAVDOS KAI GAVDOPOULA & 6290.59 \\
\hline
\end{tabular}

phytocommunity (Plantago weldenii Reichb. \& Trifolium tomentosum L.) accounted for $3 \%$ of the total MTP plant communities. At site level, Juncus bufonius (Juncaceae) occurred in most MTP sites, thus being the most common species, followed by Lythrum hyssopifolia L. (Lythraceae), Plantago weldenii (Plantaginaceae) and Callitriche brutia (Callitrichaceae).

Regarding the geographic distribution of the dominant MTP phytocommunities in Greece, there is not any obvious pattern (fig. 3). Nevertheless, the Isoetion class is mostly encountered in the islands of central and northern Aegean Sea where more humid conditions occur than in the southernmost located islands of Crete and Gavdos (sites 15,16 and 18), where the phytocommunities of Thero - Brachypodietalia and Zannichellion are encountered. The production of phytocommunity categories of figure 3 covers the site scale and does not represent each pond examined by the responsible scientific team. This explains the existence of categories that incorporate more than one characteristic class of MTP vegetation.

The Cluster analysis performed to investigate ponds with similar plant species composition revealed major differences among sites. As shown in figure 4, the vast

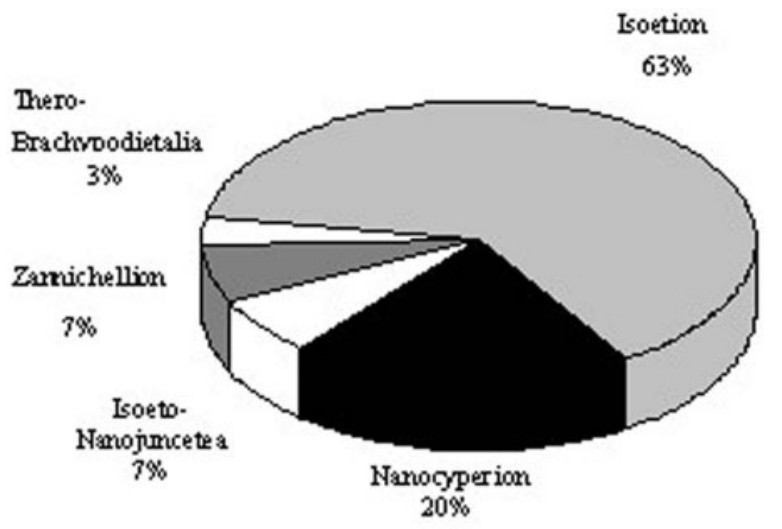

Fig. 2. Dominant phytocommunities of the Greek MTPs.

majority of the sites consisted of different plant species and only 2 groups of the sites had a relatively similar plant community structure (nearly and more than $50 \%$ similarity). Juncus bufonius was the common species that grouped sites 13 and 8 together, although the geomorphology of these sites was entirely different. Sites 5 and 4 commonly comprised of Tillaea vaillantii, Callitriche brutia and Myosurus sessilis Wats.

Differences in plant composition could be attributed to numerous environmental factors such as altitude, geology, soil type and climate. Mountainous ponds for example, comprise different plant species from ponds that are distributed in sand dunes or coastal plains. Additionally, climatic conditions could play a major role in species distribution. Areas subjected to long droughts (Southeast Aegean islands) are inhabited by species capable of tolerating such conditions.

\section{Representativity and environmental characteris-} tics of Greek MTPs

The categorization of representativity of the MTP sites was based on the ecological monitoring and sampling programme conducted for the development of Natura 2000 catalogue. Five representativity classes were used in order to describe the appearance of the typical MTP flora in each habitat. This particular index provides the ability to assess how typical composition of vegetation is at site, while at the same time comprised an indirect measurement of biodiversity.

Of the MTPs examined, $80 \%$ presented a "good" and "excellent" representativity of their characteristic phytocommunities, (fig. 5) meaning that there is a significant number of very important habitats that maintain their typical vegetation until today and should be thus managed appropriately to preserve their biodiver- 


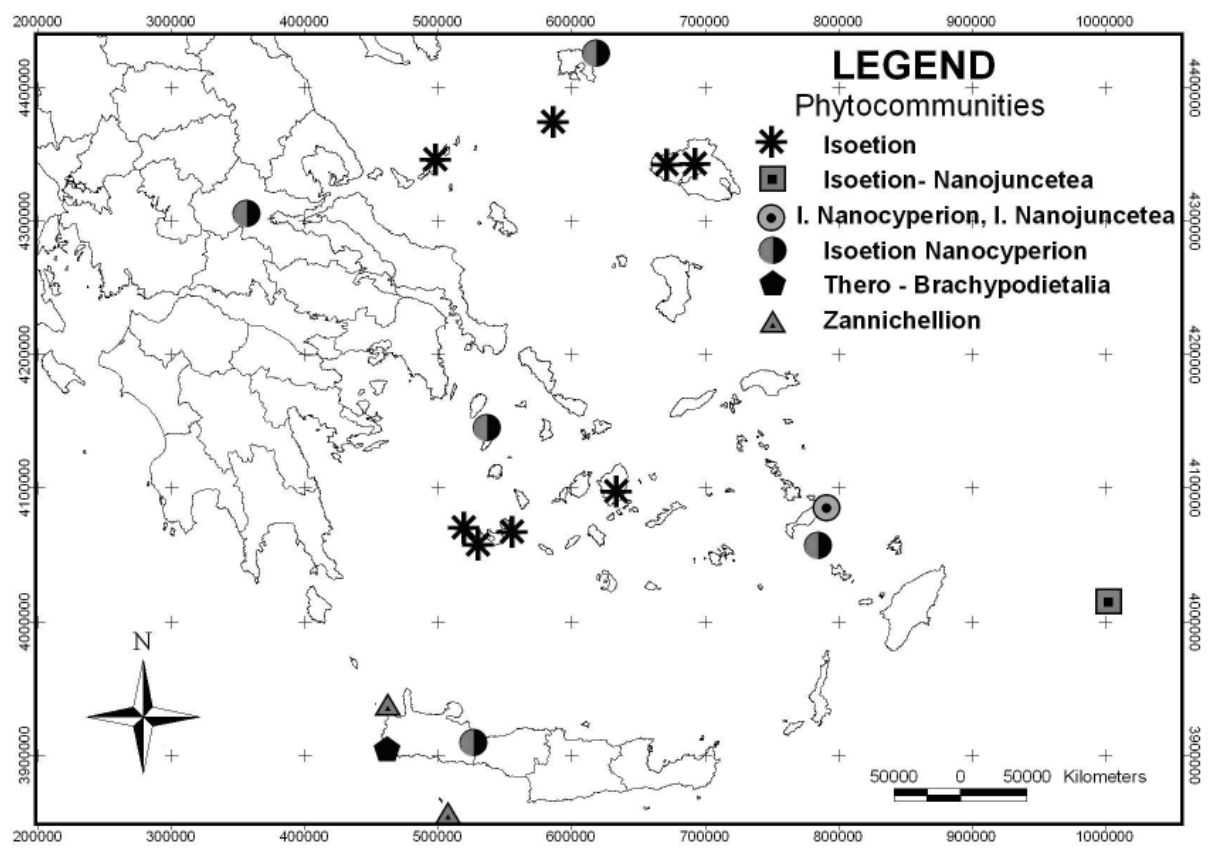

Fig. 3. Map illustrating the representative phytocommunities of each MTP site.

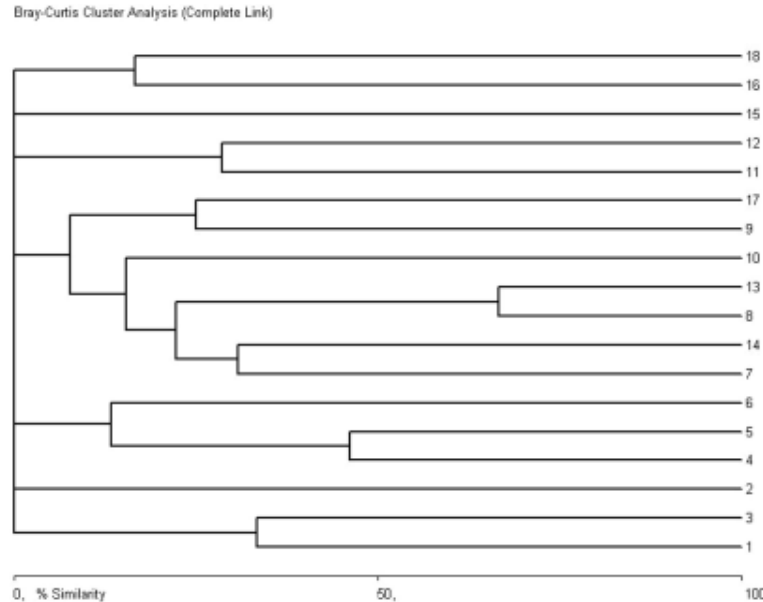

Fig. 4. Dendrogram presenting group of sites with similar plant species.

sity. "Medium" and "bad" representativity was presented by $17 \%$ of the sites indicating the existence of significantly degraded sites probably due to human interventions.

Approximately 56\% of the MTP sites are located on sedimentary geological substrate (fig. 6) of which $70 \%$

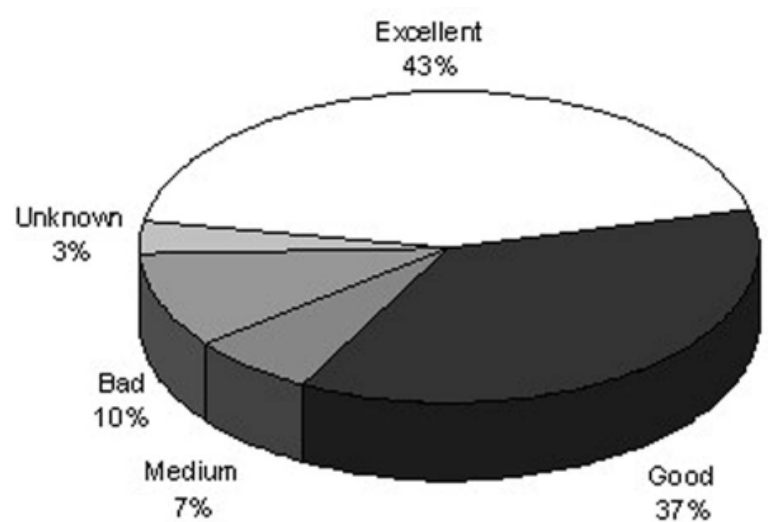

Fig. 5. Representativity of MTPs.

comprises alluvial sediments, silt and sand and 30\% consists of limestone. Siliceous formations comprise the substrate of five sites, mainly incorporating volcanic rocks. The geographic distribution of MTP's with sedimentary formations as substrate is wide, while siliceous substrate is only encountered in three islands of central Aegean Sea (in the Cyclades complex) and in one island of eastern Aegean (Nisiros) that has had volcanic activity in the past. The correlation of phytocom- 


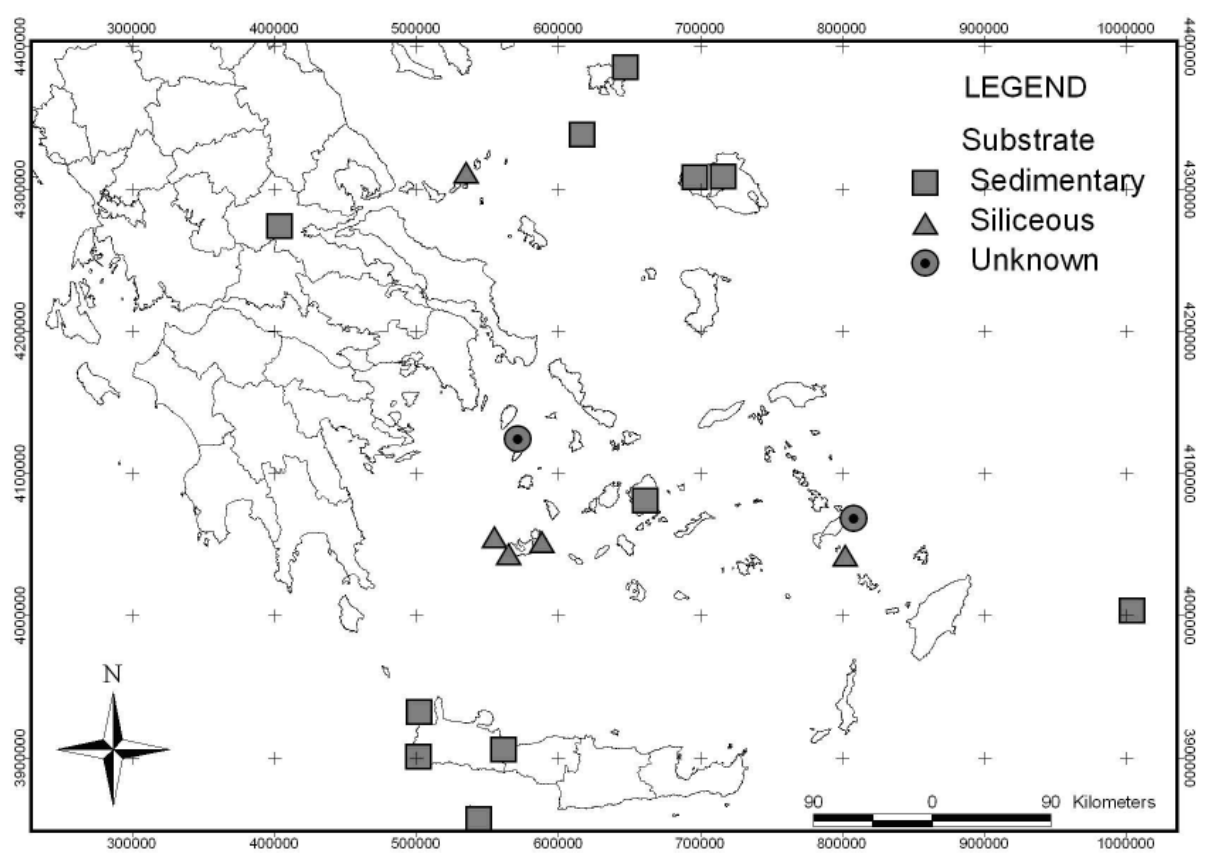

Fig. 6. Map illustrating the geology of each MTP site.

munities with the substrate types indicated that Isoetion is encountered mostly on siliceous formations since approximately $80 \%$ of the ponds containing species from the particular class have silica sediments as a geological substratum while for the other classes there is not any significant relationship with the substrate type.

The MTP's in Greece were observed mostly in lowlands since the altitude of all the sites, except the one located on Gavdos island (site 18), was below $300 \mathrm{~m}$ above sea level. Moreover, 33\% of the sites were encountered in altitudes below $30 \mathrm{~m}$ and $44 \%$ of the MTP's were located between 30 and $300 \mathrm{~m}$ of elevation while some ponds on Gavdos Island were slightly above $300 \mathrm{~m}$ (fig. 7).

\section{Threats and eco-status of Greek MTPs}

The ecological status of the MTP's indicates the pressures that they receive and illustrates significant threats due to human activities. Only 3 sites have "excellent" and "good" eco-status, reflecting minimum levels of pressure and threats, while $33 \%$ of the ponds have "medium" eco-status and approximately $40 \%$ of the sites are "at risk" (figs. 8 and 9). The sites under immediate risk are mostly located in the northern and central islands of the Aegean Sea while sites in southern and eastern Aegean Sea have mainly medium ecological status (fig 8). This pattern is probably observed due to the relatively low human pressure existing in the south-eastern part of the country where climatic conditions are not favourable for agriculture and the significant distance from urban areas (Athens) obstructing intense development activities.

All sites, except one (site 1), are affected by anthropogenic pressures such as, overgrazing, agriculture and hydrological disturbance also comprising the most common threats on MTPs throughout Greece. Only site 1 has been unaffected by anthropogenic causes while sites 2, 14 and 16 received more pressures ( 3 different categories) than the rest of the sites (table 2).

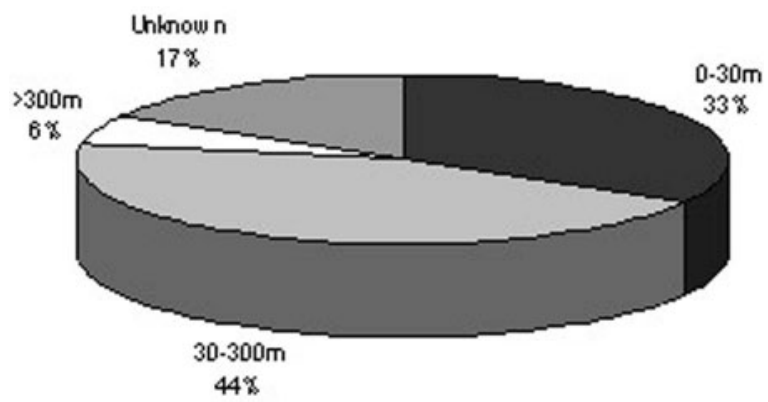

Fig. 7. Altitudinal distribution percentage of Greek MTPs. 


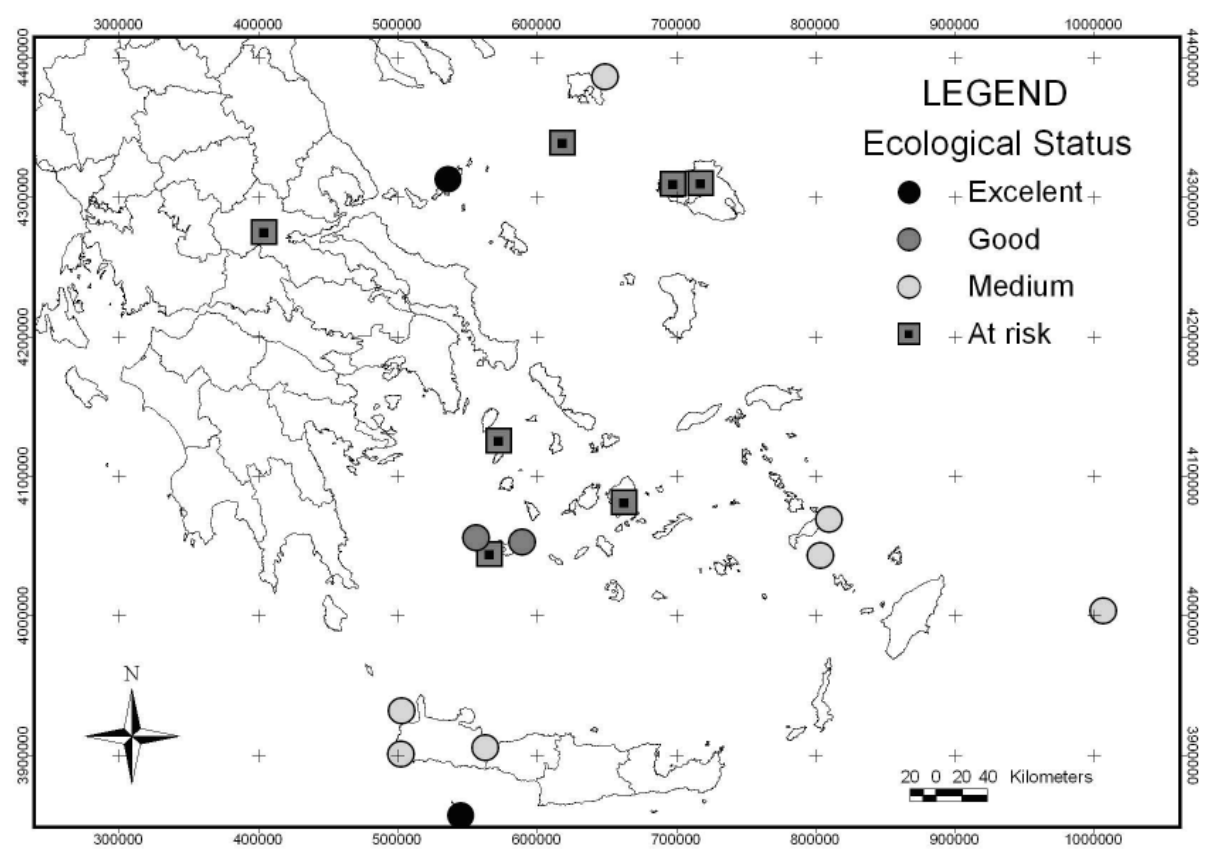

Fig. 8. Ecological status of Greek MTPs.

The pressure category that affects most of the MTP sites is agriculture which has both direct disturbances, loss of habitat through the expansion of cropland, and indirect disturbances such as water pollution. This pressure exists in $29 \%$ of all the MTP sites in Greece (figure 9) while hydrologic disturbance problems and overgrazing follow with $19 \%$ and $16 \%$ of the MTP sites, respectively. Soil excavation from the ponds is the next most common threat which is also related to agriculture and urban development while tourism pressure appears in $11 \%$ of the sites mainly due to lack off public awareness on the habitat's ecological/conservation value. The sites that are probably not under threat today represent only $3 \%$ of the total MTP sites, which is a significant figure and indicates that immediate actions should commence to protect the MTPs from potential degradation.

Agricultural activities and hydrologic destabilization are today the most significant threats to MTP habitats in Greece (table 2). Agricultural intensification in combination with the use of fertilizers and pesticides can lead to groundwater pollution, significantly affecting the ponds. Hydrologic disturbances mostly originate from human activities including direct water abstraction from the ponds and direct lowering of the groundwater level (being hydraulically connected to the ponds) as a result of aquifer overexploitation. Overgrazing is also a very important threat for the MTP's since the intensification of stockbreeding in these areas during past decades has affected the vegetation composition and species abundance to a great extent. Furthermore, soil excavation is very often related to horticulture since the dredged material is mainly used as a substrate in greenhouses and in some cases for fertilization. Finally, tourism also imposes some pressure on the habitat since $95 \%$ of the MTP sites are located on islands that receive significant number of visitors during the summer months.

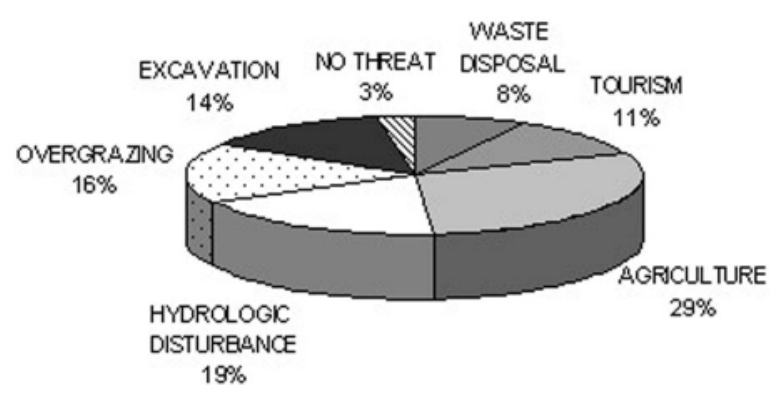

Fig. 9. Types of pressures that degrade MTPs and their percentages. 
Table 2. Table demonstrating common threats on Greek MTPs.

\begin{tabular}{|c|c|c|c|c|c|c|c|c|}
\hline$\underset{8}{8}$ & $\begin{array}{l}\frac{1}{8} \\
0 \\
\frac{3}{3} \\
\frac{\pi}{2} \\
z\end{array}$ & 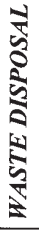 & 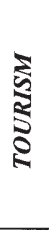 & 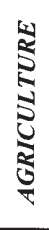 & 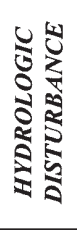 & 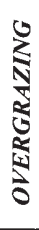 & 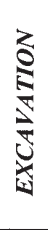 & 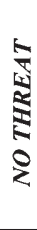 \\
\hline Site 1 & GR1430004 & & & & & & & $\sqrt{ }$ \\
\hline Site 2 & GR2440002 & $\sqrt{ }$ & & $\sqrt{ }$ & $\sqrt{ }$ & & & \\
\hline Site 3 & GR4110001 & & & $\sqrt{ }$ & & & & \\
\hline Site 4 & GR4110002 & & & & & & $\sqrt{ }$ & \\
\hline Site 5 & GR4110003 & & & & & & $\sqrt{ }$ & \\
\hline Site 6 & GR4110004 & & & & $\sqrt{ }$ & & $\sqrt{ }$ & \\
\hline Site 7 & GR4210004 & & & & $\sqrt{ }$ & & & \\
\hline Site 8 & GR4210007 & & $\sqrt{ }$ & & & & & \\
\hline Site 9 & GR4210008 & & & & $\sqrt{ }$ & $\sqrt{ }$ & & \\
\hline Site 10 & GR4220005 & & & $\sqrt{ }$ & & & & \\
\hline Site 11 & GR4220006 & & $\sqrt{ }$ & $\sqrt{ }$ & & & & \\
\hline Site 12 & GR4220007 & & & $\sqrt{ }$ & & $\sqrt{ }$ & & \\
\hline Site 13 & GR4220010 & & & & $\sqrt{ }$ & & & \\
\hline Site 14 & GR4220014 & $\sqrt{ }$ & & $\sqrt{ }$ & $\checkmark$ & & & \\
\hline Site 15 & GR4340001 & & & $\sqrt{ }$ & & & $\sqrt{ }$ & \\
\hline Site 16 & GR4340002 & & $\sqrt{ }$ & $\sqrt{ }$ & & & $\sqrt{ }$ & \\
\hline Site 17 & GR4340010 & & $\sqrt{ }$ & & & $\sqrt{ }$ & & \\
\hline Site 18 & GR4340013 & & & $\sqrt{ }$ & & $\sqrt{ }$ & & \\
\hline
\end{tabular}

\section{Discussion}

Temporary ponds are freshwater habitats which favour the establishment of unique and diverse fauna and flora communities. Due to their unstable ecological conditions, living organisms need to be highly adaptable. Comparing the flora characteristics of the Greek MTPs with the respective habitat in other Mediterranean countries several similarities were observed as well as, some differences. Isoetes community is encountered in most MTP's throughout the Mediterranean region while several endemic species are also found in different sites such as Isoetes heldreichii Wettst. in Greece, Ranunculus revelieri Boreau in Corsica, Eryngium atlanticum Batt. \& Pit., in Morocco, Artemisia molinieri Quézel, M.Barbero \& R.JLoisel, in Provence and Marsilea bartardae Launert in the Iberian Peninsula (Grillas et al. 2004a, Rhazi et al. 2004). The observed differences in flora composition at the various countries and sites are contributed to the diversity of hydrologic conditions and depend on the timing and duration of the inundation phase. The pteridophytes Isoetus, Marsilea and Pilularia have variable water requirements, whereas species of Callitriche, Ranunculus, Lythrum, Eryngium and Solenopsis depend strictly on flooding conditions (Grillas et al. 2004a, Rhazi et al. 2004, Warwick \& Brock 2003).
Thus, many local and rare species are expected to be found in these habitat types while Callitriche and Elatine are considered to be the most threatened plant species in MTPs throughout Europe (Grillas et al. 2004a, Keeley \& Zedler 1996). It was observed from the cluster analysis of the Greek MTPs that almost each pond consisted of different plant communities. This is due to the significant variety in environmental conditions observed in the examined habitat sites that present a wide spatial distribution. Particularly, the dominant climatic conditions between the southeast islands in the Aegean sea and the habitat sites in central Greece have significant differences both in seasonal and annual basis. The extended drought periods in these islands causes a very low duration of flooding in the ponds that may be classified as ephemeral or episodic while in the humid areas of the country (rainfall $>600 \mathrm{~mm}$ annually) MTPs may operate as intermittent or seasonal and therefore respective alterations in the vegetation are observed.

Common pressures were also found in various sites of Mediterranean region. Agricultural activities, water abstraction directly and indirectly from the ponds, as well as, urban development are the most commonly encountered pressures (Beja \& Alcazar 2003, Blaustein \& Schwartz 2001, Brendonck \& Williams 2000, King 1996). Additional impacts are observed in touristic areas where recreational activities often degrade the habitat and therefore measures to inform public and establish conservation schemes should be initiated at European level.

The considerable pressures imposed on the MTP habitat throughout Greece and other Mediterranean countries and the decline of the habitat's ecological status illustrate the necessity for the implementation of management and conservation measures (Boix et al. 2001, Brendonck \& Williams 2000). Particularly, increasing public awareness on the values of the MTPs and explaining the benefits that could derive from their conservation is a very important issue when aiming to achieve a long-term protection while a stakeholder participatory approach in designing management schemes is also a prerequisite for achieving a broad consensus.

Management of MTP habitats should also focus on re-establishing the hydroperiod of each pond by applying hydrologic models and other scientific tools so as to estimate the natural duration of flooding, potential human interferences and effects of climate change. Interfering with the morphology of the pond by altering / deepening the bed should be avoided, especially during the dry period, since it may cause loss of plant seeds and macroinvertebrates (Nicolet et al. 2004). 
Conservation measures should be undertaken on ponds of different sizes and it would be preferable to include many small ponds rather that one large pond, since in this way a substantial variety of microhabitats can be preserved. Additionally, the creation of MTP(s) in highly degraded habitat sites can be also a beneficial option given the existence of thorough ecological and hydrologic studies (Grillas et al. 2004a).

A simple typology system for temporary ponds should be developed in order to assist in the classification of the ponds according to their characteristics and key components which mostly determine their biotic properties. Additionally, an ecological monitoring program should be initiated for assessing the status of each habitat and for managing the phytocommunities so as to ensure maintenance of the typical MTP species and limited competition from other common species.

\section{Acknowledgments}

This study was conducted with the contribution of Natura 2000 database and the LIFE-Nature project entitled: 'Actions for the conservation of Mediterranean Temporary Ponds in Crete'.

\section{References}

Angélibert S., Marty P., Céréghino R., Giani N. 2004. - Seasonal variations in the physical and chemical characteristics of ponds: implications for biodiversity conservation. Aquat. Conserv., 14, 439456.

Beja P. \& Alcazar R. 2003. - Conservation of Mediterranean temporary ponds under agricultural intensification: an evaluation using amphibians. Biol. Conserv., 114, 317-326.

Belk D. 1998. - Global status and trends in Ephemeral pond invertebrate conservation: implication for Californian fairy shrimp. Pages 147-150 in Ecology, Conservation, and Management of Vernal Pool Ecosystems. Witham C.W., Bauder E.T., Belk D, Ferren W.R. Jr. \& Ornduff R. (eds.). California Native Plant Society, CA.

Blaustein L. \& Schwartz S.S. 2001. - Why study ecology in temporary pools? J. Zool., 47, 303-312.

Boix D., Sala J., Moreno-Amich R. 2001. - The faunal composition of Espolla Pond (NE Iberian Peninsula): the neglected biodiversity of temporary waters. Wetlands, 21, 577-592.

Brendonck L. \& Williams W.D. 2000. - Biodiversity in Wetlands of dry regions (drylands). Biodiversity in wetlands: assessment function and conservation, 1, 181-194.

European Commission DG Environment. 2003. - Interpretation manual of European Union habitats- directive. Natura 2000, Nature and biodiversity EUR 25, 32-33.

Graham TB. 2002. - Survey of aquatic macro invertebrates and amphibians at Wapatki National Monument, Arizona, USA: An eva- luation of selected factors affecting species richness in ephemeral pools. Hydrobiologia, 486, 215-224.

Grillas P., Gauthier P., Yavercovski N., \& Perennou C. 2004a. - Mediterranean Temporary Pools; Volume 1 - Issues relating to conservation, functioning and management. Station biologique de la Tour du Valat. $118 \mathrm{p}$.

Grillas P., Gauthier P., Yavercovski N., Perennou, C. 2004b. - Mediterranean Temporary Pools, Volume 2 - Species information sheets. Station biologique de la Tour du Valat. $128 \mathrm{p}$.

Jakob C., Poizat G., Veith M., Seitz A. \& Crivelli A.J. 2003. - Breeding phenology and larval distribution of amphibians in a Mediterranean pond network with unpredictable hydrology. Hydrobiologia, 499, 51-61.

Keeley J.E. \& Zedler P.H. 1996. - Characterization and global distribution of vernal pools. Ecology, Conservation, and Management of Vernal Pool Ecosystems. California Native Plant Society, Sacramento.

King J.L. 1996. - Loss of Diversity as a Consequence of Habitat Destruction in California Vernal Pools. Ecology, Conservation, and Management of vernal pool ecosystems. California Native Plant Society, Sacramento.

Lahr J., Diallo A.O., Gadji B., Diouf P.S., Bedaux J.J.M., Badji A., Ndour K.B., Andreasen J.E. \&Van Straalen N.M. 2000a. - Ecological effects of experimental insecticide applications on invertebrates in Sahelian temporary ponds. Environ. Toxicol. Chem., 19, 1278-1289

Lahr J., Gadji B. \& Dia D. 2000b. - Predicted buffer zones to protect temporary pond invertebrates from ground-based insecticide applications against desert locusts. Crop Prot., 19, 489-500.

Leidy R.A. \& White E.G. 1996. - Toward an Ecosystem Approach to Vernal Pool Compensation and Conservation. Ecology, Conservation, and Management of vernal pool ecosystems. California Native Plant Society, Sacramento.

Madhyastha M.N., Shashikumar K.C. \& Rekha P.D. 2000. - Temporary ponds - a neglected ecosystem. Proceedings of Lake 2000: Restoration of Lakes and wetlands. Section 6, Limnology, Watershed Hydrology and Monitoring. Paper 6. Bangalore, India.

McAleece, N. 1997. Biodiversity Professional. The Natural History Museum \& the Scottish Association for Marine Science.

Nicolet P., Biggs J., Fox G., Hodson M.J., Reynolds C., Whitfield M. \& Williams P. 2004. - The wetland plant and macroinvertebrate assemblages of temporary ponds in United Kingdom and Wales. Biol. Conserv., 120, 261-278.

Rhazi M., Grillas P., Charpentier A. \& Médail F. 2004. - Experimental management of Mediterranean temporary pools for conservation of the rare quillwort "Isoetes setacea". Biol. Conserv., 118, 675-684.

Roshier D.A., Whetton P.H., Allan R.J. \& Robertson I. 2001. - Distribution and persistence of temporary wetland habitats in arid Australia in relation to climate. Austral Ecol., 26, 371-384.

Warwick N.W.M. \& Brock M.A. 2003. - Plant reproduction in temporary wetlands: the effects of seasonal timing, depth, and duration of flooding. Aquat. Bot., 77, 153-167.

Williams D.D. 1997. - Temporary ponds and their invertebrate communities. Aquat. Conserv., 7, 105-117. 